\title{
Genetic analyses of fertility and predictor traits in Holstein herds with low and high mean calving intervals and in Jersey herds
}

\author{
M. Haile-Mariam, ${ }^{*} \dagger^{1}$ P. J. Bowman, ${ }^{*} \dagger$ and J. E. Pryce ${ }^{*} \dagger$ \\ *Biosciences Research Division, Department of Primary Industries, Bundoora, Victoria 3083, Australia \\ †Dairy Futures Cooperative Research Centre, Bundoora, Victoria 3083, Australia
}

\begin{abstract}
Genetic parameters were estimated with the aim of identifying useful predictor traits for the genetic evaluation of fertility. For this study, data included calving interval (CI), days from calving to first service (CFS), pregnancy diagnosis, lactation length (LL), daily milk yield close to $90 \mathrm{~d}$ of lactation (milk yield), and survival to second lactation on Australian Holstein and Jersey cows. The effect of level of fertility, measured here as CI, on correlations among traits was investigated by dividing the Holstein herds into those that managed short CI (proxy for seasonal-calving herds) and long CI (proxy for herds that practice extended lactations). In all cases, genetic correlations of CI with CFS, pregnancy, and LL were high $(>0.7)$. Genetic correlations between fertility and predictor traits were generally similar in the 2 Holstein herd groups and in Jerseys. However, some differences in both the direction and strength of correlations were observed. In Jerseys, the genetic correlation between CI and survival was positive, but in Holstein herds, this correlation was negative. Particularly in low mean CI herds, the correlation suggests that cows with a genetic potential for longer CI were more likely to be culled. The genetic correlation of CI with survival was intermediate in high mean CI Holstein herds. Furthermore, Jersey cows with a high genetic potential for milk yield had a higher chance of surviving than those with low genetic potential. In contrast, the genetic correlation between milk yield and survival in low mean CI Holstein herds was near zero. The high genetic correlation between CI and LL suggests that LL could be used as proxy for CI in cows that do not calve again. Although the phenotypic variance for CI in high mean CI herds was nearly twice that in Jerseys and low mean CI herds, we found no bull reranking for CI due to having daughters in low or high mean CI herds. However, the ranges in estimated breeding values (EBV) were narrower in low mean CI
\end{abstract}

Received April 29, 2012.

Accepted September 14, 2012.

${ }^{1}$ Corresponding author: Mekonnen.HaileMariam@dpi.vic.gov.au herds than in high mean CI herds. The genetic trend in cows and bulls showed that CI EBV were increasing by 0.3 to $0.8 \mathrm{~d} / \mathrm{yr}$ in both Holstein and Jersey. Phenotypically, CI was increasing by $2 \mathrm{~d} / \mathrm{yr}$ in high mean CI Holstein herds and by $1 \mathrm{~d} / \mathrm{yr}$ in Jersey and low mean CI Holstein herds. However, in recent years, both phenotypic and genetic trends have stabilized. In summary, if the main trait for genetic evaluation of fertility is CI, predictor traits such as milk yield, survival, LL, and other fertility traits can be used in joint analyses to increase reliability of bull EBV. If the genetic evaluation is to be carried out simultaneously for Holstein and Jersey using the same variance-covariance matrix, survival should not be used as a predictor because its correlation with CI is different in Jersey than in Holstein. On the other hand, LL could be used instead of CI for cows that do not calve again in both breeds and herd groups.

Key words: fertility trait, predictor, correlation, breeding value

\section{INTRODUCTION}

Fertility levels in dairy cattle have been declining, particularly in Holsteins (Royal et al., 2000; Lucy, 2001; Liu et al., 2008; Sun et al., 2010; Sewalem et al., 2010). If the unfavorable trend continues, model projections by Maas et al. (2009), taking the dairy cattle of the United Kingdom as an example, suggest that sustaining the size of the national herd may not be possible due to lack of adequate replacement heifers caused by prolonged calving intervals (CI). One of the reasons for the decline in fertility of dairy cows is unfavorable genetic correlations between milk yield traits and fertility and intense selection for increased milk yield (e.g., Pryce and Veerkamp, 2001). The effect of low fertility on profitability is twice as high in seasonal-calving herds as in herds that calve year round (Haile-Mariam et al., 2010) because of the reduced survival of less fertile cows in seasonal-calving herds. Including fertility as part of a selection index for total profit could halt the downward genetic trend and assist in achieving compact seasonal calving and breeding patterns. However, 
there are major challenges for achieving a favorable genetic gain in fertility: (1) a lack of good quality data, (2) definition of the selection objective trait; and (3) inadequate selection pressure on fertility traits within a multitrait selection index.

In the absence of adequate mating and pregnancy data, genetic evaluations for fertility can be based on CI. For example, in Australia, only $72 \%$ of the cows with previously recorded calving dates have CI and only $15 \%$ have days from calving to first service interval (CFS). Lack of data affects the reliability of bull EBV (Haile-Mariam and Goddard, 2007). Furthermore, both CI and CFS are often censored because some cows (1) do not calve again, (2) are not mated, or (3) are not recorded as mated, and so are excluded from the current evaluation even if culled due to poor fertility. This creates a problem mostly for young first-proof bulls, because data on some of their progeny that calve late or mate late in the season will not be included until the subsequent genetic evaluation. This pattern of data availability may cause reranking (instability) of bulls between consecutive genetic evaluation runs, even for bulls with reasonably high reliabilities. Another shortcoming of CI as a measure of fertility is that, in countries where seasonal, split, and year-round calving systems are practiced, differences exist in mean and standard deviation between herds (Haile-Mariam and Goddard, 2007; Haile-Mariam et al., 2008), which may affect the stability of bull rankings between consecutive genetic evaluations runs.

By using multitrait analyses of fertility traits that include predictors of fertility in genetic evaluations, it has been shown that bias (over- or underestimation of EBV) is reduced and reliability of bull EBV is improved (e.g., Sun et al., 2010). For example, survival is jointly analyzed with CI in Irish cattle genetic evaluations (Olori et al., 2002), and this approach was recommended for the Australian evaluation (Haile-Mariam et al., 2004), where both studies showed improved reliability of bull EBV for CI. The benefit of multitrait analyses of milk yield with fertility traits on the reliability of bull EBV has been demonstrated (e.g., Sewalem et al., 2008; Sun et al., 2010). However, where fertility data are recorded on almost all cows, the advantage of including information on culling (Holtsmark et al., 2008) and other fertility traits (e.g., days open or CI; Sun et al., 2010) on the reliability of fertility EBV (e.g., nonreturn rate or CFS) is reported to be small.

In situations such as those in Australia, where only about $5 \%$ of the cows that calved recently have pregnancy data and $15 \%$ have mating data, the benefit of using additional information on culling, milk yield, and lactation length when estimating breeding values for fertility is expected to be high. However, the benefits of different predictor traits may depend on the strength and consistency of the genetic association between the predictor traits and the fertility trait(s) that are used for genetic evaluations. These associations may be influenced by calving system, breed, and herd management. For example, in seasonal-calving herds where a CI of close to $365 \mathrm{~d}$ is targeted, better fertility is given more emphasis than other traits (Harris et al., 2005; Haile-Mariam et al., 2008), and these herds may use bulls with higher fertility EBV than year-round or split-calving herds (i.e., herds with high mean CI that practice extended lactation). Thus, genetic and phenotypic trends for important fertility traits could vary between herds. All these reasons could influence the accuracy of EBV and ultimately the genetic deterioration or improvement of fertility traits.

The main aim of this study was to examine the benefit of using data on culling, milk yield, and lactation length to calculate EBV for fertility traits in 2 groups of Holstein herds that differed in their emphasis on fertility (measured as CI) as well as in the Jersey breed. The specific objectives were to (1) examine if heritability estimates for fertility traits and their relationship with predictor traits in these 3 groups differ, (2) examine if bulls rank similarly for CI in the groups, and (3) estimate genetic and phenotypic trends for CI in these 3 groups.

\section{MATERIALS AND METHODS}

\section{Data}

Calving, lactation length, daily milk yield recorded close to $90 \mathrm{~d}$ of lactation, survival, pregnancy, and mating data of Holstein and Jersey breeds were extracted from the Australian Dairy Herd Improvement Scheme (ADHIS) database. Herds with at least 100 calving records between January 1995 and December 2010 were selected. Bulls used in AI programs with at least 5 daughters were included in this study. Additionally, the study was restricted to first-parity cows that calved between 18 and 36 mo of age.

The following traits were analyzed: CI, CFS, pregnancy rate, lactation length $(\mathbf{L L})$, daily milk yield recorded close to $90 \mathrm{~d}$ of lactation (hereafter, milk yield), and survival from first to second lactation (hereafter, survival). Ninety-day milk yield was chosen because 90 $\mathrm{d}$ was close to the time when most cows were mated. Cows were considered pregnant, and coded 100, if the age of fetus at pregnancy diagnosis was at least $30 \mathrm{~d}$, and were coded 0 otherwise. To be valid, CI had to have a minimum length of $290 \mathrm{~d}$; CI between 550 and $762 \mathrm{~d}$ were set at a maximum of $551 \mathrm{~d}$ to minimize the influence of extremely long intervals on both the 
variance and mean. This edit was included because of preliminary analyses that compared the heritability of CI based on different restrictions. Calving intervals of $>762 \mathrm{~d}$ ( $>2$ yr and $1 \mathrm{mo}$ ) or $<290 \mathrm{~d}$ were set to missing because they were assumed to be incorrect. Cows with missing CI but with a recorded LL of $\geq 550 \mathrm{~d}$ were included as having the maximum CI of 551 d. Similarly, LL of $\geq 100 \mathrm{~d}$ were accepted as valid and LL $>450 \mathrm{~d}$ were set at a maximum of $451 \mathrm{~d}$. A minimum length of CFS of $15 \mathrm{~d}$ was considered valid and the maximum length was set at $260 \mathrm{~d}$. To minimize possible bias due to exclusion of data (i.e., due to culling, selection, or missing), all cows that had previous calving dates were included provided they had at least one valid record for any trait.

\section{Statistical Analyses}

Three data sets were formed to achieve the objectives of the current study; that is, to determine if relationships between fertility traits and possible predictors were similar in the 2 types of Holstein herds that differ by mean CI (i.e., high and low mean CI) and in the Jersey breed. To classify Holstein herds into low and high mean CI groups, the mean CI for herds was calculated by fitting age at calving, herd, and year and month of calving. Herd solutions from this analysis were then used to divide herds into the 2 groups. The first data set consisted of Holstein herds with a mean CI $\geq 397$ $\mathrm{d}$, designated as high mean CI herds (i.e., year-round or split-calving herds). The second data set included Holstein herds with mean CI of $\leq 396$ d (i.e., predominantly seasonal-calving herds), designated low mean CI herds. Because of this, the Holstein cow population was divided into 2 groups of roughly equal size. The third data set consisted of all Jersey cows, which were mostly from seasonally calving herds where over $60 \%$ of the calvings occur within a 3-mo period of the year. Means and standard deviations of different fertility and possible predictor traits and structure of the data sets are shown in Table 1.

Estimation of genetic parameters and prediction of breeding values were performed using ASReml (Gilmour et al., 2009). In the models used for estimating both genetic parameters and prediction of breeding values, the following effects were fitted: herd-year-season of calving (HYS), month of calving, and age at first calving (covariate) as fixed effects. Either the sire or animal with a full pedigree relationship was included as random effect. Although fitting an animal model was preferred for both estimating genetic parameters and calculating breeding values, sire models were used for estimating genetic parameters. This was because a large number of iterations and computer time were required for the

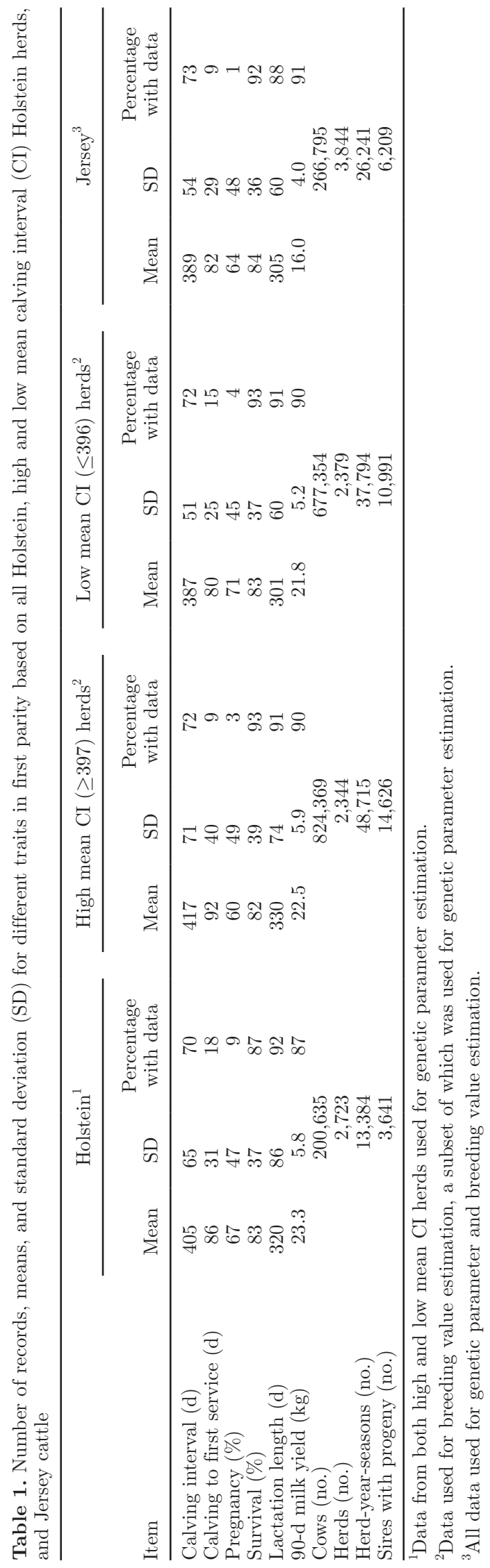

Journal of Dairy Science Vol. 96 No. 1, 2013 
calculation of variance-covariance estimates involving several traits. Estimating parameters based on a relatively large representative data set using a multitrait sire model is likely to be a better approach compared with an animal model with less data. On the other hand, to obtain reliable breeding value estimates that account for all relationships, an animal model was used. The available pedigree information on all animals was traced back to the 1950s, and animals with unknown parents were grouped based on their birth year, country of origin, and sex according to standard ADHIS genetic evaluation procedures (ADHIS, 2004).

\section{Relationships Between Fertility and Possible Predictor Traits}

First, genetic parameters were estimated for the Holstein breed using data from both high and low mean CI herds to obtain parameters that were relevant to the whole Australian Holstein population. First-parity data on CI, CFS, survival, pregnancy rate, LL, and 90-d milk yield were used for this analysis. In addition, genetic parameters were estimated for high and low mean CI Holstein herds and separately for the Jersey breed. When estimating genetic parameters, convergence was facilitated by using starting values from a set of univariate, bivariate, trivariate, et cetera, models until a 6 -trait model was reached. A 6-trait model including pregnancy rate did not converge when data of high and low mean CI Holstein herds were analyzed separately because of the relatively small amount of pregnancy data.

The statistical model in matrix notation can be written as

$$
\mathbf{y}_{\mathrm{T}}=\mathbf{X}_{\mathrm{T}} \mathbf{b}_{\mathrm{T}}+\mathbf{Z}_{\mathrm{T}} \mathrm{s}(\mathbf{a})_{\mathrm{T}}+\mathbf{e}_{\mathrm{T}},
$$

where $\mathbf{y}_{\mathbf{T}}$ is the observation on all traits, $\mathbf{X}_{\mathbf{T}}$ is the incidence matrix for fixed effects (HYS, age, and month of calving) for each trait, $\mathbf{b}_{\mathrm{T}}$ is the vector of all fixed effects, $\mathbf{Z}_{\mathrm{T}}$ is incidence matrix for random effects, $\mathbf{s}_{\mathbf{T}}$ is vector of random sire effects or $\mathbf{a}_{\mathbf{T}}$ is vector of animal effect, and $\mathbf{e}_{\mathbf{T}}$ is the vector of random residual effects. The expectation are $\mathbf{E}\left(\mathbf{y}_{\mathbf{T}}\right)=\mathbf{X}_{\mathbf{T}} \mathbf{b}_{\mathbf{T}}, \mathbf{E}\left(\mathbf{s}_{\mathbf{T}}\right)=0$ or $\mathbf{E}\left(\mathbf{a}_{\mathbf{T}}\right)=0$, and $\mathbf{E}\left(\mathbf{e}_{\mathbf{T}}\right)=0$, with the following variancecovariance matrix:

$$
\begin{gathered}
\operatorname{Var}(\mathbf{s})=\mathbf{G} \otimes \mathbf{A}_{s} \text { for sire model, } \\
\operatorname{Var}(\mathbf{a})=\mathbf{G} \otimes \mathbf{A}_{a} \text { for animal model, and } \\
\operatorname{Var}(\mathbf{e})=\mathbf{R} \otimes \mathbf{I}_{e}
\end{gathered}
$$

where $\mathbf{G}$ and $\mathbf{R}$ are variance-covariance matrices of size 6 when all the Holstein data were analyzed and of size 5 when data of low or high mean CI herd or Jersey only were analyzed; $\mathbf{A}_{s}$ or $\mathbf{A}_{a}$ is additive genetic relationship among sires or animals, respectively, $\mathbf{I}$ is an identity matrix, and $\otimes$ is the Kronecker product. In the estimation of covariances, cows that did not survive to the next lactation did not have CI, so the residual (i.e., matrix $\mathbf{R}$ ) covariance between CI and survival was set to zero in all analyses that involved these 2 traits.

\section{Genotype by Herd Mean Cl Interaction for $\mathrm{Cl}$}

The importance of a genotype by environment interaction $(\mathbf{G} \times \mathbf{E})$ for CI was assessed based on 2 approaches. The first approach considered CI recorded in high and low mean CI herds as different traits and estimated genetic correlation between them. This was achieved using a bivariate model that had the additive genetic effect of sire as a random effect. Additional analyses for $\mathrm{G} \times \mathrm{E}$ using a bivariate model were performed by redefining CI in the low mean CI herds as calving rate $(\mathbf{C R})$, because calving early in a season is considered to be a better measure of fertility in strictly seasonal-calving systems (Harris et al., 2005). To assess if differences in the definition of $\mathrm{CR}$ were important when examining $\mathrm{G} \times \mathrm{E}, 3 \mathrm{CR}$ measures were defined using CI information for cows that calved and culling information for cows that were in low mean CI herds, but did not calve again because they were culled for poor fertility. For the first measure (CR1), cows were coded as 100 when CI was $\leq 396$ d (i.e., calving within a 13-mo interval, which is below the mean CI of all Holstein cows in the data set) and as 0 for cows with CI of $\geq 397 \mathrm{~d}$. The second measure (CR2) was defined in the same way as CR1 for cows that calved, but the cows that were coded 0 also included cows without CI if they were reported as culled for poor fertility. The third measure (CR3) was defined by coding cows with CI of $\leq 388 \mathrm{~d}$ as 100 (a more stringent level of fertility) and those that had CI of $\geq 389 \mathrm{~d}$ and those that were recorded as culled for fertility as 0 . Including cows that did not calve again using their culling information increased the number of cows with data in low mean CI herds by $4 \%$.

The bivariate model to examine $\mathrm{G} \times \mathrm{E}$ for $\mathrm{CI}$ included the same fixed and random effects, expectations, and variances as that in model [1]. However, the error variance-covariance matrix was a diagonal matrix of size 2 and the sire variance-covariance matrix was of size 2 .

In addition, to assess whether the stability of bull EBV was affected by the difference in mean CI of herds where their progeny performed, correlations between 
EBV from high and low mean CI herds were calculated and compared with the correlation between EBV for the same bulls calculated from randomly splitting herds into 2 equally sized groups; EBV were calculated for each data set. Then, correlations between the EBV for CI based on bulls with 50,100, and 500 or more progeny were estimated for Holstein herds with high and low mean CI and for herds split into 2 random groups. In both scenarios, EBV for CI were estimated from a 6-trait and a single-trait animal model to see if correlations between EBV from the multitrait model differed from those of the single-trait model.

The second approach for assessing the importance of $\mathrm{G} \times \mathrm{E}$ tested for a scaling effect by examining if the predictive power of CI EBV of sires was affected by the mean CI of the herd where their daughters performed (e.g., Kearney et al., 2004). The performance of daughters in high versus low mean CI herds were examined using linear regression of daughter $\mathrm{CI}$ on the EBV of their sires. The sire EBV used were first predicted using the CI data of all the Holstein cows (both high and low CI herds). The EBV for CI of sires were regressed on CI of their daughters in a model that included all fixed effects. This regression model can be written in matrix notation as

$$
\mathbf{y}=\mathbf{X b}+\beta_{\mathrm{SIRE}} \mathrm{EBV}_{\mathrm{CI}}+\mathbf{e},
$$

where $\mathbf{y}$ is progeny $\mathbf{C I}, \mathbf{X b}$ are fixed effects (HYS, age, and month of calving), $\boldsymbol{\beta}_{\text {SIRE }}$ is coefficient of regression of daughter CI on sire EBV for CI obtained from analyses of data of all cows (low and high mean CI herds together), $\mathbf{E B V}_{\mathbf{C I}}$ is CI EBV of sires, and $\mathbf{e}$ is error variance with $\mathbf{I}_{e}$.

\section{Genetic and Phenotypic Trends in Different Herds}

To assess if the genetic trend differed between Holsteins and Jerseys, genetic trends were calculated based on the CI EBV for bulls with at least 5 progeny. The EBV for CI were predicted based on CI alone and based on CI estimated from a 6-trait analysis of CI with pregnancy, CFS, LL, survival, and milk yield. When calculating genetic trends from the multitrait model, data of all Holstein herds were used to obtain CI EBV using the 6-trait variance-covariance matrix. For Jerseys, a 5-trait model without survival was used to estimate EBV. However, for ease of interpretation, genetic trends based on a single-trait model were plotted. Genetic trends based on cows with at least one CI record from high and low mean CI herds and Jersey cows were also calculated. For comparison purposes, phenotypic trends for CI were plotted by year of calv- ing of cows in the high and low mean CI Holstein herds as well as in Jersey herds.

\section{RESULTS}

\section{Cow Performance}

The mean CI, CFS, survival, pregnancy rate, LL, and milk yield for all Holstein cows, low and high mean CI Holstein herds, and Jersey herds are shown in Table 1. The mean CI of high mean CI herds was approximately 1 mo longer than that of low mean CI herds (Table 1). In general, the mean performance of Jersey cows was similar to that of the low mean CI Holstein herds for all traits except milk yield and pregnancy rate. This was expected because the Jerseys were in predominantly seasonal-calving herds, with $60 \%$ of their calvings limited to 3 mo of the year. The proportion of cows with valid records was lowest for pregnancy rate and highest for survival. Relatively less pregnancy data were recorded in Jersey herds. Recording of mating data was higher in low mean CI herds, reflecting the emphasis on fertility traits in these herds compared with that in high mean CI herds and Jersey herds (Table 1).

Table 1 also shows that survival to second lactation was similar in the 2 Holstein herd groups and in Jerseys, varying only from 82 to $84 \%$. Information on culling reasons in Australian dairy cattle was incomplete but the available data show that culling on fertility among cows that did not survive to second lactation was similar in the 2 Holstein herd groups $(16 \%)$ and slightly lower in Jersey herds (13\%). Culling for reasons other than fertility (mostly for low milk production) was 55, 50, and $48 \%$ in Jersey, low mean CI Holstein herds, and high mean CI Holstein herds, respectively.

\section{Relationships Between Fertility and Possible Predictor Traits}

Genetic parameter estimates in Tables 2, 3, 4 and 5 show that heritabilities of all fertility and predictor traits, except for milk yield, were low (0.01-0.05). The heritability estimate of 90-d milk yield in Jerseys was higher than that in the 2 groups of Holstein herds. In addition, heritability estimates of survival and LL were slightly higher in Jerseys than in the 2 Holstein groups. Although differences between heritabilities estimated for the same trait in Holstein herd groups and Jerseys were small, difference in phenotypic variances, particularly for CI and CFS, were large. For example, the phenotypic variance for CI in high mean CI Holstein herds was nearly double that in Jersey and low mean CI Holstein herds. For almost all traits, the phenotypic 
variances in Jerseys were smaller than in the 2 Holstein herd groups.

Genetic correlations showed that CI was highly correlated with CFS, pregnancy, and LL. The genetic antagonism between milk yield and CI (0.3-0.4) was also similar in all groups. In most cases, the genetic correlations were higher than the residual correlations (Tables 2 to 5). However, the level of residual and genetic correlations between CI and LL were similar, suggesting that cows with long lactations also have long CI. This reflects the part and whole relationship between the 2 traits.

Most genetic correlations between fertility and predictor traits were similar in the 2 Holstein herd groups and in Jerseys, but a few correlations were substantially different. The most notable difference was in the correlation between CI and survival (Tables 2 to 5 ). In Jerseys, long CI and high survival were positively genetically correlated, but in both low and high mean CI Holstein herds, they were negatively correlated. Particularly in low mean CI Holstein herds, survival and CI were strongly negatively correlated $(-0.61)$ so that cows with genetic potential for long CI were culled. The negative genetic relationship between CI and survival was intermediate in high mean CI herds.

Furthermore, Jersey cows with a high genetic potential for milk yield had a greater chance of surviving than those with a low genetic potential. Interestingly, in low mean CI Holstein herds, the genetic correlation between milk yield and survival was near zero. In high mean CI Holstein herds, the genetic correlations between milk yield and survival were intermediate. However, environmental relationships between survival and milk yield were similar (0.12 to 0.17$)$ in both Holstein herds and Jersey. Phenotypically, the 90-d milk yields of cows that survived to second lactation were $1.31 \pm$ $0.01,1.26 \pm 0.01$, and $1.36 \pm 0.02 \mathrm{~L} / \mathrm{d}$ more than cows culled in the high and low mean CI Holstein herds and Jersey, respectively. This represents a $6 \%$ difference in daily milk yield (i.e., between culled and survived cows) in the 2 Holstein herd groups and an $8 \%$ difference in Jersey, confirming that milk yield was a more important consideration when making culling decisions in the Jersey breed than in the 2 Holstein herd groups.

The genetic correlation between survival and LL was strong and positive in Jerseys but negative in low mean CI Holstein herds, where it was possible that cows with poor fertility had longer lactations and were more likely to be culled. In contrast, this correlation was effectively zero in high mean CI herds. The difference in association between survival and LL in the 2 Holstein herd groups and Jerseys was at the genetic level because all the residual correlations between LL and survival were positive but close to zero (Tables 2 to 5 ).

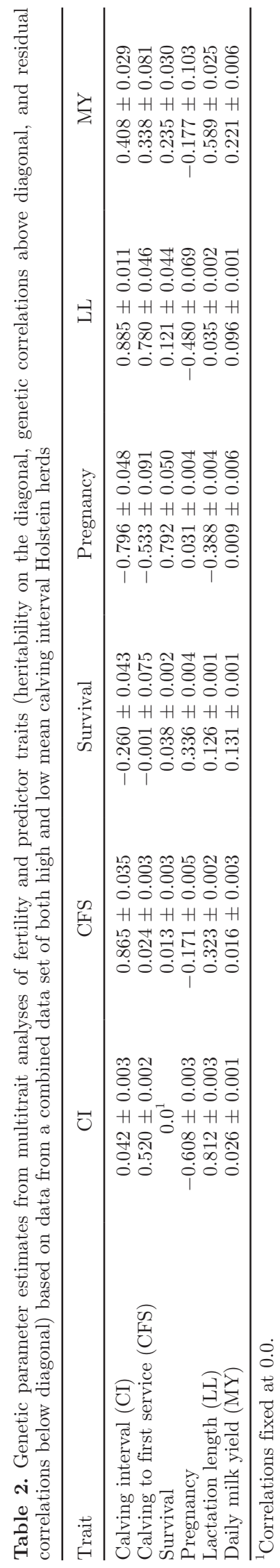


Table 3. Genetic parameter estimates for high mean calving interval Holstein herds ${ }^{1}$ from multitrait analyses of fertility and candidate predictor traits (heritability on the diagonal, genetic correlations above diagonal, and residual correlations below diagonal)

\begin{tabular}{lccrrr}
\hline Trait & CI & CFS & Survival & LL & MY \\
\hline Calving interval (CI) & $0.036 \pm 0.003$ & $0.891 \pm 0.049$ & $-0.239 \pm 0.060$ & $0.9395 \pm 0.01$ & $0.365 \pm 0.041$ \\
Calving to first service (CFS) & $0.617 \pm 0.003$ & $0.025 \pm 0.005$ & $-0.251 \pm 0.10$ & $0.788 \pm 0.064$ & $0.407 \pm 0.079$ \\
Survival & $0.0^{2}$ & $0.028 \pm 0.004$ & $0.034 \pm 0.003$ & $-0.010 \pm 0.061$ & $0.313 \pm 0.043$ \\
Lactation length (LL) & $0.847 \pm 0.001$ & $0.402 \pm 0.004$ & $0.093 \pm 0.001$ & $0.033 \pm 0.003$ & $0.517 \pm 0.037$ \\
Daily milk yield (MY) & $0.047 \pm 0.002$ & $0.022 \pm 0.004$ & $0.126 \pm 0.002$ & $0.094 \pm 0.002$ & $0.221 \pm 0.008$ \\
Phenotypic variance & $5,122 \pm 12.4$ & $1,022.6 \pm 6.8$ & $1,366.7 \pm 3.1$ & $5,823.4 \pm 12.7$ & $14.76 \pm 0.04$ \\
\hline
\end{tabular}

${ }^{1}$ Herds with mean CI $\geq 397$ d.

${ }^{2}$ Correlations fixed at 0.0 .

The genetic correlation between CI and LL was highest in high mean CI herds and lowest in Jerseys. However, the level of correlations between these 2 traits in all herds and breeds was strong, suggesting that LL can be used as proxy for CI for cows that did not calve again.

\section{Genotype by Herd Mean Cl Interaction for Cl}

Table 6 shows results from additional analyses carried out to explore the presence of $\mathrm{G} \times \mathrm{E}$ for CI. Despite a large difference in variance between high and low mean CI herds, the genetic correlation between the 2 groups was effectively 1 . In low mean CI herds, a proxy for seasonal-calving herds, defining CI as CR did not change the correlation between the 2 measures of fertility (CI and CR). Similarly, changing the threshold of CI from 396 to $388 \mathrm{~d}$ for deciding CR and including cows culled for poor fertility in the noncalved group did not affect the genetic correlation (Table 6). In low mean CI herds, the consequence of changing the definition of fertility from CI to CR and including cows culled for fertility marginally increased the heritability value.

Correlations between bull EBV for CI from univariate analyses estimated on their progeny performance in high and low mean CI herds were slightly lower than those between EBV estimated by splitting herds randomly into 2 groups (Table 7 ). This provided some indication of possible $\mathrm{G} \times \mathrm{E}$ when bull $\mathrm{EBV}$ were based on $\geq 50$ or $\geq 100$ daughters. Correlations between EBV were higher when multitrait models were used to estimate breeding values than when single-trait models were used in both situations (where herds were divided into high and low mean CI herds or randomly split into 2 groups). As expected, the correlations between EBV increased as the number of progeny increased (Table 7).

Coefficients of regression of daughter CI on EBV of their sires for CI were $0.45 \pm 0.01$ if the CI of the daughter was observed in low mean CI herds and 0.69 \pm 0.02 if the CI of the daughter was observed in high mean CI herds, reflecting a difference in scale between the 2 herds.

\section{Genetic and Phenotypic Trends in Different Herds}

The genetic trend analysis for Holstein bulls from 1986 to 2003 indicated that CI was increasing by 0.81 $\mathrm{d} / \mathrm{yr}$ (when estimated from a multitrait model) and $0.71 \mathrm{~d} / \mathrm{yr}$ (when estimated from a univariate model). The genetic trend based on cows in high and low mean CI herds from the multitrait model show that CI EBV were increasing by 0.85 and $0.80 \mathrm{~d} / \mathrm{yr}$ between 1991 and 2007, respectively. A slightly lower rate of increase of 0.83 and $0.77 \mathrm{~d} / \mathrm{yr}$ for cows in high and low mean CI herds, respectively, were observed when a univariate model was used to estimate CI EBV (Figure 1). We observed a difference of approximately $6 \mathrm{~d}$ in CI EBV between bulls and cows, which aligns with the expected

Table 4. Genetic parameter estimates for low mean calving interval Holstein herds ${ }^{1}$ from multitrait analyses of fertility and candidate predictor traits (heritability on the diagonal, genetic correlations above diagonal, and residual correlations below diagonal)

\begin{tabular}{lccrrr}
\hline Trait & CI & CFS & Survival & LL & MY \\
\hline Calving interval (CI) & $0.034 \pm 0.003$ & $0.746 \pm 0.093$ & $-0.610 \pm 0.058$ & $0.891 \pm 0.019$ & $0.311 \pm 0.050$ \\
Calving to first service (CFS) & $0.478 \pm 0.003$ & $0.012 \pm 0.004$ & $-0.346 \pm 0.137$ & $0.684 \pm 0.105$ & $0.229 \pm 0.114$ \\
Survival & $0.0^{2}$ & $0.008 \pm 0.004$ & $0.030 \pm 0.003$ & $-0.278 \pm 0.08$ & $0.049 \pm 0.055$ \\
Lactation length (LL) & $0.827 \pm 0.001$ & $0.310 \pm 0.004$ & $0.128 \pm 0.001$ & $0.021 \pm 0.002$ & $0.460 \pm 0.051$ \\
Daily milk yield (MY) & $0.044 \pm 0.002$ & $0.021 \pm 0.004$ & $0.123 \pm 0.002$ & $0.088 \pm 0.002$ & $0.221 \pm 0.009$ \\
Phenotypic variance & $2,829.6 \pm 7.8$ & $310.2 \pm 1.8$ & $1,248.7 \pm 3.1$ & $3,217.8 \pm 7.8$ & $12.84 \pm 0.04$ \\
\hline
\end{tabular}

${ }^{1}$ Herds with mean CI $\leq 396 \mathrm{~d}$.

${ }^{2}$ Correlations fixed at 0.0 . 
Table 5. Genetic parameter estimates for the Jersey breed from multitrait analyses of fertility and candidate predictor traits (heritabilities on the diagonal, genetic correlations above diagonal, and residual correlations below diagonal)

\begin{tabular}{lccrcc}
\hline Trait & CI & CFS & \multicolumn{1}{c}{ Survival } & LL \\
\hline Calving interval (CI) & $0.026 \pm 0.004$ & $0.828 \pm 0.105$ & $0.293 \pm 0.084$ & $0.777 \pm 0.038$ & $0.421 \pm 0.058$ \\
Calving to first service (CFS) & $0.587 \pm 0.005$ & $0.024 \pm 0.008$ & $-0.006 \pm 0.161$ & $0.532 \pm 0.134$ & $0.311 \pm 0.124$ \\
Survival & $0.0^{1}$ & $0.013 \pm 0.007$ & $0.054 \pm 0.005$ & $0.731 \pm 0.045$ & $0.513 \pm 0.041$ \\
Lactation length (LL) & $0.745 \pm 0.001$ & $0.359 \pm 0.006$ & $0.216 \pm 0.002$ & $0.045 \pm 0.005$ & $0.657 \pm 0.038$ \\
Daily milk yield (MY) & $0.070 \pm 0.002$ & $0.034 \pm 0.006$ & $0.173 \pm 0.002$ & $0.154 \pm 0.002$ & $0.334 \pm 0.013$ \\
Phenotypic variance & $2,662.9 \pm 9.2$ & $409.1 \pm 4.2$ & $1,185.2 \pm 3.8$ & $2,325.3 \pm 7.3$ & $6.66 \pm 0.03$ \\
\hline
\end{tabular}

${ }^{1}$ Correlations fixed at 0.0 .

genetic lag between sires and daughters. The similar genetic trend of cows in the low and high mean CI herds was because approximately $90 \%$ of the cows were sired by bulls used in both groups of herds. However, 686 and 310 bulls with 30 or more progeny were used in only high or only low mean CI herds, respectively. The mean EBV for CI from a multitrait model for 686 bulls with 30 or more progeny that were only used in high mean CI herds was $0.8 \mathrm{~d}$ and that of 310 bulls used only in low mean CI herds was marginally lower $(-1.2$ d) than the average EBV ( $5.6 \mathrm{~d}$ ) of all Holstein bulls. This differential use of bulls may explain the widening genetic trend in cow CI EBV between the 2 Holstein herd groups that has appeared in recent years. But the phenotypic trends for CI per year of calving in high mean CI herds $(2.1 \mathrm{~d})$ was almost double that in low mean CI herds $(1.2 \mathrm{~d})$ over the calving period of 1994 to 2008 (Figure 2).

In Jerseys, the genetic trends for bulls increased by 0.62 and $0.32 \mathrm{~d} / \mathrm{yr}$ between 1987 and 2003 when CI EBV were estimated from a multitrait and univariate model (Figure 3), respectively. The genetic trend in cows showed a slightly lower rate of increase at about 0.5 and $0.3 \mathrm{~d} / \mathrm{yr}$ from the multitrait and univariate models (Figure 3), respectively. The phenotypic trend in Jersey was $1.1 \mathrm{~d} / \mathrm{yr}$ for cows that calved between 1994 and 2008 (Figure 2).

\section{DISCUSSION}

The differences in mean CI and CFS and in the amount of mating data collected between low and high mean CI herds reflect the difference in performance and importance of fertility between seasonal and yearround or split-calving herds (i.e., herds that practices extended lactation). This is similar to the observations made by Haile-Mariam et al. (2008) on a subset of the data used for this study. The distributions of calvings were also similar, where over $60 \%$ of the calvings in low mean CI herds occurred between July and September. These results show that both calving system and herd mean CI can be used to subdivide herds into uniform groups.

Genetic correlations between CI and survival and between CI and milk yield in low mean CI herds were generally similar to correlations estimated for these traits in seasonal-calving herds in Ireland (Berry et al., 2010). Holtsmark et al. (2008) reported a genetic correlation of culling (opposite of survival) of -0.41 with 305-d protein yield in Norwegian Red cattle, which agrees with our result for Jerseys. Slightly negative genetic correlations between survival and milk yield were reported by Dematawewa and Berger (1998) based on Holstein cattle in the United States. Unfavorable genetic correlations between survival and fertility similar

Table 6. Measures of genotype $\times$ environment interaction, assessed as the correlation between high and low mean calving interval (CI) Holstein herds, where fertility in low CI herds is also defined as calving rate

\begin{tabular}{|c|c|c|c|c|c|}
\hline \multirow[b]{2}{*}{ Item } & \multirow{2}{*}{$\begin{array}{c}\text { High mean CI herds }{ }^{1} \\
\text { CI }(d)\end{array}$} & \multicolumn{4}{|c|}{ Low mean CI herds ${ }^{2}$} \\
\hline & & CI (d) & CR $1 \%$ & $\mathrm{CR} 2 \%$ & $\mathrm{CR} 3 \%$ \\
\hline Mean (SD) & $420(71)$ & $388(52)$ & $70(46)$ & $68(47)$ & $61(49)$ \\
\hline Phenotypic variance & $4,531(12)$ & $2,355(7)$ & $1,874(5)$ & $1,964(5)$ & $2,144(6)$ \\
\hline Heritability $^{3}$ & $0.044 \pm 0.004$ & $0.035 \pm 0.003$ & $0.022 \pm 0.002$ & $0.028 \pm 0.003$ & $0.028 \pm 0.003$ \\
\hline Genetic correlation ${ }^{3,4}$ & & $0.981 \pm 0.015$ & $-0.991 \pm 0.016$ & $-0.988 \pm 0.014$ & $-0.991 \pm 0.013$ \\
\hline
\end{tabular}

${ }^{1}$ Herds with mean CI $\geq 397$.

${ }^{2}$ Herds with mean CI $\leq 396$. CR $1 \%=$ cows with CI $\leq 396$ coded 100 and CI $\geq 397$ coded $0 ;$ CR $2 \%=$ cows with CI $\leq 396$ coded 100 and CI $\geq 397$ and cows culled for fertility coded 0 ; CR3 $\%=$ cows with CI $\leq 388$ coded 100 and CI $\geq 389$ and cows culled for fertility coded 0 .

${ }^{3}$ Values \pm standard error of estimates.

${ }^{4}$ Between CI in high mean CI herds and low mean CI herds. 
Table 7. Correlations between bull EBV for calving interval (CI) when data from Holstein herds classified by mean herd CI (high and low) and randomly split data were used in a univariate and multitrait model to predict EBV

\begin{tabular}{lccccc}
\hline & & \multicolumn{2}{c}{ High and low CI herds } & & \multicolumn{2}{c}{ Even and odd herds $^{2}$} \\
\cline { 3 - 3 } Progeny (no.) & Bulls (no.) & Single trait & Multitrait & & Single trait \\
\hline 50 & 3,319 & $0.661^{\mathrm{a}}$ & 0.696 & $0.704^{\mathrm{b}}$ & 0.714 \\
$\geq 100$ & 1,174 & $0.673^{\mathrm{a}}$ & 0.731 & $0.706^{\mathrm{b}}$ & 0.734 \\
$\geq 500$ & 339 & 0.798 & 0.838 & & 0.797 \\
\hline
\end{tabular}

${ }^{\mathrm{a}, \mathrm{b}}$ Difference in correlation was significant $(P=0.05)$ when number of progeny was 50 or 100 and CI EBV was based on single trait (i.e., CI).

${ }^{1}$ Herds with mean CI $\geq 397$ and herds with mean CI $\leq 396$, respectively.

${ }^{2}$ Herds spilt into 2 randomly based on the last digit in the herd identification.

to those in the Jersey breed found here were reported by Dematawewa and Berger (1998). Sewalem et al. (2008) also reported that, phenotypically, the relative risk of culling did not change for Jersey and Ayrshire breeds with increasing days open, compared with that in Holsteins, in which the risk of culling increased. The positive genetic correlation of survival with milk yield, LL, and CI in Jerseys in the current study implies that fertility is perceived to be less of a problem in Jerseys than in low mean CI Holstein herds.

The observation that genetic correlations among fertility traits such as CI, pregnancy, and CFS were higher than environmental correlations is in agreement with previous studies (Haile-Mariam et al., 2004; Liu et al., 2008). Lactation length, which was highly correlated with CI both genetically and environmentally, was recorded on over $90 \%$ of cows with a previous calving date. Lactation length can replace CI for cows that are culled and do not have CI. This is important because fewer than $70 \%$ of cows in the Australian data had CI data, and the proportion of cows with data on other fertility traits was even less, making LL an important predictor of fertility.

The genetic correlations between survival and other traits such as CI, milk yield, and LL in low mean CI herds compared with those in Jerseys and in high mean CI herds showed that fertility is a key trait in low mean CI herds. The observation that more cows were culled or sold for reasons other than fertility (mostly milk yield) in Jerseys compared with the 2 Holstein herd groups confirms the findings from the variancecovariance estimates. That similar levels of culling for fertility and for reasons other than fertility were observed in the 2 Holstein herds does not necessarily agree with the observed difference in genetic correlations between CI and survival (Table 3 vs. Table 4).

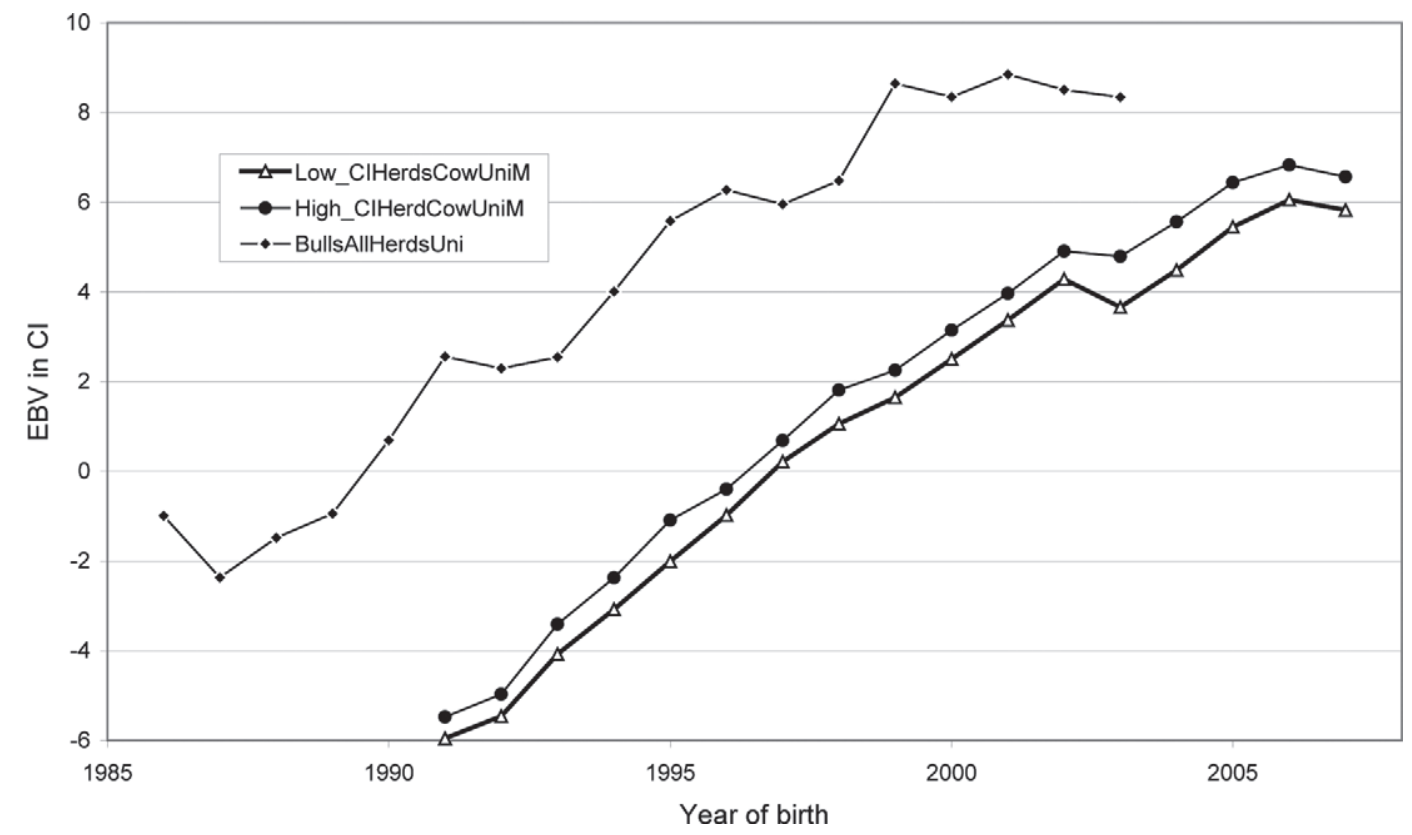

Figure 1. Genetic trend in calving interval (CI) of bulls with at least 5 progeny (BullsAllHerdsUni) and of cows with at least 1 CI record in high (High_CIHerdCowUniM) and low (Low_CIHerdsCowUniM) mean CI Holstein herds from univariate model. 


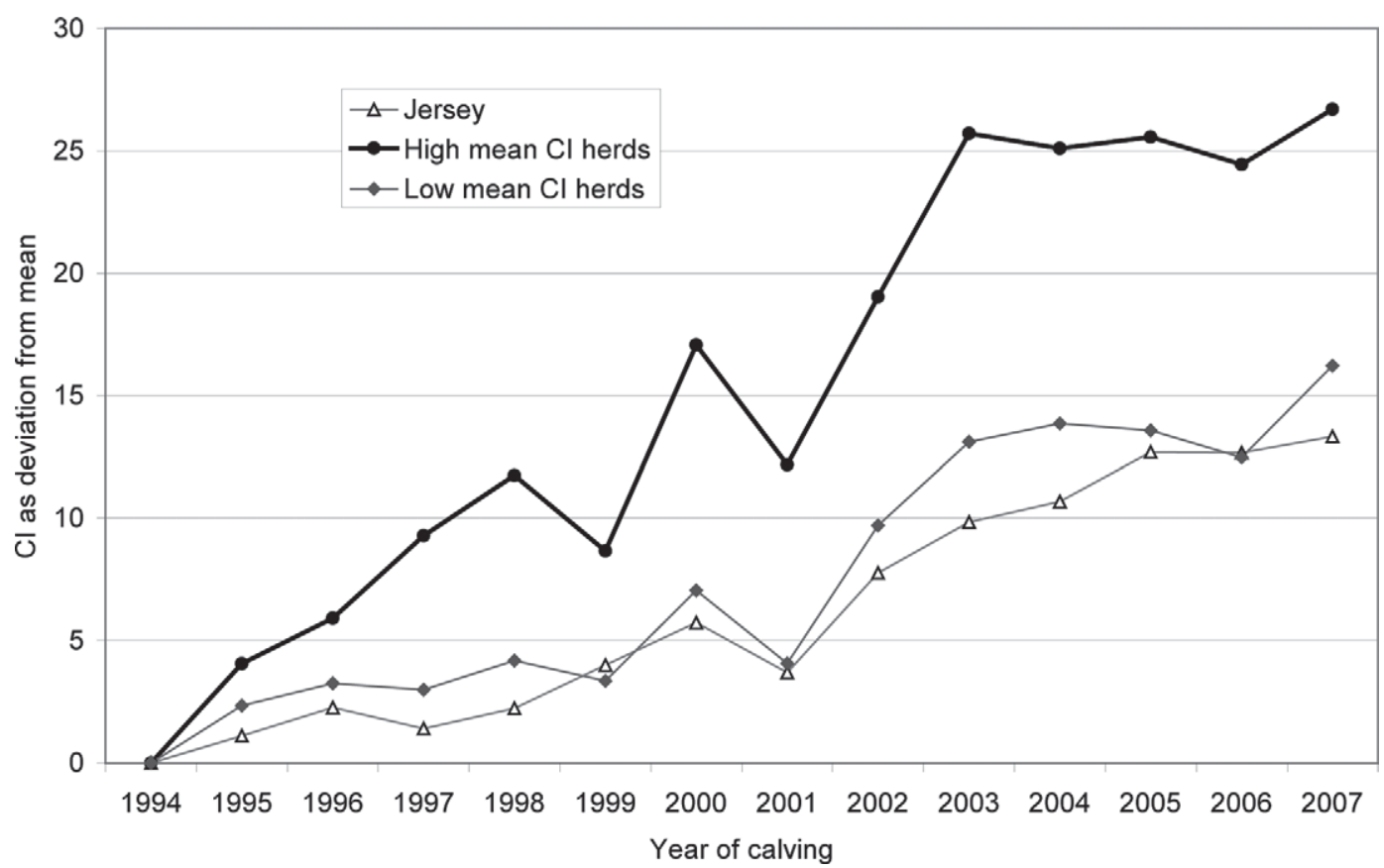

Figure 2. Phenotypic trend in calving interval (CI) by year of calving in Jersey herds, high mean CI Holstein herds, and low mean CI Holstein herds.

This could be due to the incomplete nature of the data on reasons for culling. For bulls with $\geq 100$ progeny, the correlations between CI EBV and the proportion of their progeny culled at the end of the first lactation was marginally higher (0.38) in low mean CI Holstein herds than in high mean CI Holstein herds (0.21). This supports the relative importance of fertility in predominantly seasonal-calving herds that manage short CI. This contrasted with Jerseys, in which the correlation between CI EBV and proportion of progeny culled was

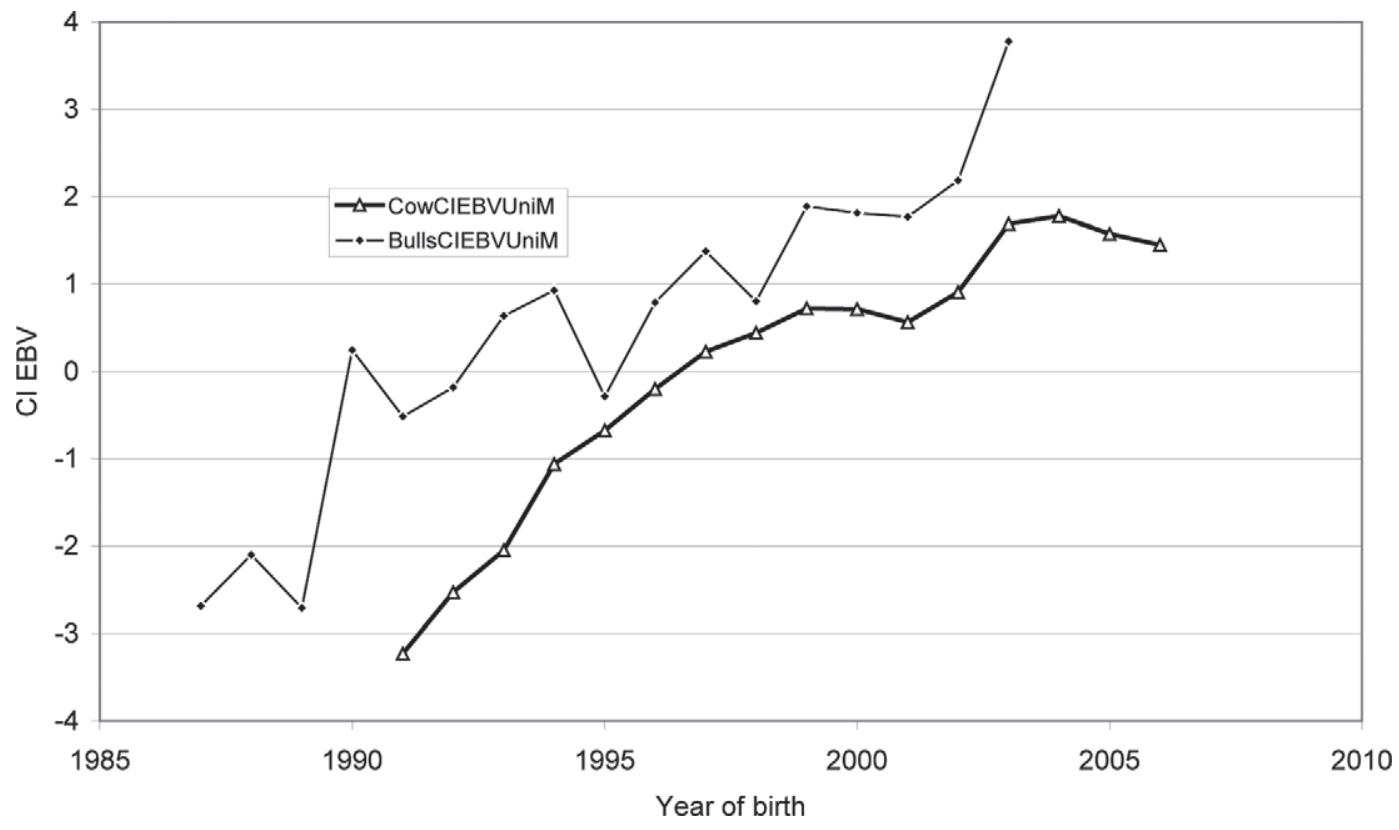

Figure 3. Genetic trend in calving interval (CI) of bulls with at least 5 progeny (BullsCIEBVUniM) and of cows with at least 1 CI record (CowCIEBVUniM) in Jersey herds from univariate model. 
-0.01 , showing that culling has no relationship with fertility and confirming the variance-covariance estimates. The differences in emphasis on fertility observed between the 2 Holstein herd groups suggest that the pool of bulls available for producers in the Holstein breed should be wider and should specifically include high-fertility bulls to give producers enough options. It also makes sense for farmers with low mean CI herds to select bulls of high fertility (Kearney et al., 2004; Haile-Mariam et al., 2008). Furthermore, traits that are important when farmers make culling decision should be emphasized when determining economic values of traits in the profit index for optimum overall genetic progress (Norman et al. 2007).

When the main trait available for genetic evaluation is CI, predictor traits such as milk yield, survival, LL, and other fertility traits can be used in joint analyses for the genetic evaluation of fertility. However, the usefulness of the indicator traits to predict fertility depends on the direction and strength of the association in the population of cows that are evaluated simultaneously using the same variance-covariance matrix. Currently in Australia, genetic evaluation for all breeds is carried out simultaneously; that is, using the same set of genetic parameters. In this study, we found that the association between fertility traits and predictor traits varied. In particular, the reasons for culling (voluntary as well as involuntary) varied, making the usefulness of survival from current lactation to next lactation as a predictor of fertility less reliable. In addition, correlations between traits, particularly those involving survival, could change over time depending on the perceived problems of farmers and the criteria they use for making culling decision. This suggests that if traits such as survival are going to be used as predictors of fertility, the direction of the correlation, at least, should be the same for the population in which it is used as a predictor.

The phenotypic variance for CI in both high and low mean CI herds was higher when estimated using a multivariate model (Tables 2 to 4) than when estimated using a univariate model (Table 6), suggesting that multitrait models account for selection (e.g., Sun et al., 2010). The observation that the genetic trends for CI estimated from a multitrait model were slightly higher than those from a univariate model also support this and agrees with Sewalem et al. (2010).

Recent estimates of genetic correlations for CI between seasonal and year-round (or split) calving herds in Australia showed that the correlation is about 0.8 (Haile-Mariam et al., 2008), but these were estimated with a large standard error. The current estimates show that the correlation is effectively 1 , meaning that no bull reranking occurs for $\mathrm{CI}$ in low and high mean CI herds. However, the ranges in EBV were narrower in low mean CI herds than in high mean CI herds (a scaling effect). The coefficients of regression of daughter CI on their sires' EBV for CI were below the expected value of 0.5 when predicted based on data from low mean CI herds and were $>0.5$ when predicted in high mean CI herds. This reflects the difference in variance between the 2 groups of herds. Analyzing CI after logtransformation within the HYS, as described by HaileMariam and Goddard (2007), increased the regression in low mean CI herds to $0.56 \pm 0.02$ and reduced the regression in high mean CI herds to $0.63 \pm 0.02$. Part of the reason for the discrepancy from the expectation could be related to the low reliability of the EBV. Kearney et al. (2004) reported a regression value of 0.37 to 0.5 for similar fertility traits in grazing versus confinement system of dairy production in the United States.

In low mean CI herds, when CR was redefined by lowering the CR to $388 \mathrm{~d}$ from 396 and considering cows culled due to poor fertility, the mean CR was $61 \%$, which is the same as that reported by Harris et al. (2005) for calving within $42 \mathrm{~d}$ after the start of the planned calving season for New Zealand dairy herds. Moreover, the heritabilities of $\mathrm{CR}$ in Table 6 were similar to those reported by Harris et al. (2005) for calving within $42 \mathrm{~d}$ after the start of the planned calving season.

Comparisons of phenotypic and genetic trends in the 2 Holstein herd groups and in Jersey herds showed that almost all the phenotypic trend in CI in low mean CI herds was due to genetics. In Jerseys and high mean CI Holstein herds, about one-third of the increase in CI over time was due to genetic deterioration and the rest was due to nongenetic reasons. The increase in phenotypic trend in CI in high mean CI herds that was not accounted for by the genetic trend could be due in part to herd management decisions, where farmers delay breeding cows with high potential for milk yield.

A reduced level of genetic deterioration in fertility was observed in Jerseys compared with the 2 Holstein herd groups despite having more emphasis on milk and a lack of emphasis on fertility, as observed by the positive genetic correlations of survival with high milk yield, longer lactation, and longer CI (Table 5). This may be related to the historically intense selection for milk yield in Holsteins. Currently, CI for Jersey and low mean CI Holstein herds were similar, showing the same level of problem, and the level of genetic antagonism between milk yield and CI was similar in both breeds and in the 2 herd groups. However, the genetic deterioration in fertility traits in Jersey is less than in Holstein, which is in agreement with Norman et al. (2009), based on US data. It would be interesting to determine if the reasons for the difference in deterioration 
are associated with difference in selection emphasis; for example, on type traits such as angularity and overall type, which are correlated with fertility. The genetic correlation between overall type and CI is lower $(\sim 0.01)$ in Jersey than in Holstein $(\sim 0.3$, our unpublished Australian data). The combination of intense selection on milk yield with selection on overall type and angularity may have contributed to greater deterioration in Holsteins. To limit any further deterioration in fertility, it is recommended that steps be taken to include fertility in a multitrait selection index (with each trait weighted by its economic value) for use in all breeds.

The increase in CI observed in the current study was similar to that observed in dairy cattle in many other countries (Hare et al., 2006). For example, in the United States, the increase in CI in first-parity Holstein and Jersey was 1.1 and $0.62 \mathrm{~d} / \mathrm{yr}$, respectively, for cows that calved between 1980 and 2004. Even in countries such as Sweden, where there has been selection for fertility for some decades, mean CI increased from 12.6 mo in 1974 to 13.3 mo in 2004 (Petersson et al., 2007).

The genetic trends observed in the 2 Holstein herd groups for CI were similar to those observed in Germany (Liu et al., 2008), Canada (Sewalem et al., 2010), Denmark (Sun et al., 2010), and the United States (VanRaden et al., 2004). Most of these studies noted that genetic deterioration has stabilized in these populations in recent years. The genetic trends in Australian herds are also starting to stabilize. However, CI in Australian herds, particularly in low mean CI herds and in Jerseys, are still low by international standards, which may be due to emphasis on reproductive efficiency where seasonal calving is still important.

The different rate of genetic trend between males and females that we observed in Jersey cattle agrees with the higher genetic trend in bulls than in cows reported for Holstein cattle in Germany (Liu et al., 2008). The clear genetic lag between bulls and cows observed in Holstein data in the current study agree with that reported in US Holstein cattle by Norman et al. (2009). Although both genetic and phenotypic trends in fertility in the Holstein breed have stabilized in recent years, it is not clear if the genetic trend of cows will have to reach the level of bulls before a meaningful improvement in fertility is achieved.

\section{CONCLUSIONS}

In this study, genetic correlations between fertility and predictor traits such as milk yield and lactation length were found to be similar in the 2 groups of Holstein herds that were identified as managing longer or shorter CI, as well as in Jersey herds. However, the genetic correlation between CI and survival was mark- edly different in Holstein and Jersey populations and between Holstein herds that differed in their mean CI. This is important, because if the genetic evaluation of fertility is to be carried out simultaneously using the same variance-covariance matrix for different populations, such as breeds or herd groups, at least the direction of genetic association among the traits should be the same. Furthermore, the variance-covariance estimates showed that CI is more important in selection decisions in seasonal-calving herds than in Jersey or high mean CI Holstein herds because of its strong association with survival. The importance of fertility in low mean CI Holstein herds (seasonal calving) also suggests that the continued success of this system depends, to some extent, on the availability of high fertility bulls. Both genetic and phenotypic trends in fertility traits have been declining in both Holstein and Jersey breeds in Australian until recently. The trend in the last few years shows some improvement as a result of incorporating fertility in the economic index.

\section{ACKNOWLEDGMENTS}

Funding for this project is provided by the Australian Dairy Herd Improvement Scheme (ADHIS) and Dairy Futures Cooperative Research Centre (Melbourne, Australia). Data is provided by ADHIS. We thank Michael Goddard and Ben Hayes (both of Department of Primary Industries Victoria, Melbourne, Australia) for their comments on the draft manuscript.

\section{REFERENCES}

ADHIS (Australian Dairy Herd Improvement Scheme). 2004. ABV Handbook Cows N Genes Workshop Manual, Melbourne, Australia.

Berry, D. P., J. F. Kearney, K. Twomey, A. R. Cromie, and R. D. Evans. 2010. Revision of the fertility and health genetic evaluations for Irish Holstein-Friesian dairy cattle. Proc. 9th World Congr. Genet. Appl. Livest. Prod., Leipzig, Germany. Accessed Oct. 23, 2012. http://www.kongressband.de/wcgalp2010/assets/pdf/0642. pdf.

Dematawewa, C. M. B., and P. J. Berger. 1998. Genetic and phenotypic parameters for 305-day yield, fertility, and survival in Holsteins. J. Dairy Sci. 81:2700-2709.

Gilmour, A. R., B. J. Gogel, B. R. Cullis, and R. Thompson. 2009. ASReml User Guide, Release 3.0. VSN International Ltd., Hemel Hempstead, UK.

Haile-Mariam, M., P. J. Bowman, and M. E. Goddard. 2004. Genetic parameters of fertility traits and their genetic correlation with production, type, workability, live weight, survival index and somatic cell count. Aust. J. Agric. Res. 55:77-87.

Haile-Mariam, M., P. J. Bowman, and M. E. Goddard. 2010. Calculation of lifetime net income per year (LTNI/year) of Australian Holstein cows to validate the Australian profit ranking of their sires. 2. Validation of the Australian profit ranking of sires and test for genotype by environment interaction based on LTNI/year. Anim. Prod. Sci. 50:767-774.

Haile-Mariam, M., M. J. Carrick, and M. E. Goddard. 2008. Genotype by environment interaction for fertility, survival, and milk production traits in Australian dairy cattle. J. Dairy Sci. 91:4840-4853. 
Haile-Mariam, M., and M. E. Goddard. 2007. An alternative measure of fertility for genetic evaluation of dairy cattle. Pages 445-448 in Proc. 17th Assoc. Adv. Anim. Breeding Genet. (AAABG) Conf. University of New England, Armidale, Australia.

Hare, E., H. D. Norman, and J. R. Wright. 2006. Trends in calving ages and calving intervals for dairy cattle breeds in the United States. J. Dairy Sci. 89:365-370.

Harris, B., J. E. Pryce, Z. Z. Xu, and W. A. Montgomerie. 2005. Fertility breeding values in New Zealand, the next generation. Interbull Bull. 33:47-50.

Holtsmark, M., B. Heringstad, P. Madsen, and J. Ødegård. 2008. Genetic relationship between culling, milk production, fertility, and health traits in Norwegian Red cows. J. Dairy Sci. 91:4006-4012.

Kearney, J. F., M. M. Schutz, and P. J. Boettcher. 2004. Genotype by environment interaction for grazing versus confinement. II. Health and reproduction traits. J. Dairy Sci. 87:510-516.

Liu, Z., J. Jaitner, F. Reinhardt, E. Pasman, S. Rensing, and R. Reents. 2008. Genetic evaluation of fertility traits of dairy cattle using a multiple-trait animal model. J. Dairy Sci. 91:4333-4343.

Lucy, M. C. 2001. Reproductive loss in high-producing dairy cattle: Where will it end? J. Dairy Sci. 84:1277-1293.

Maas, J. A., P. C. Garnsworthy, and A. P. F. Flint. 2009. Modeling responses to nutritional, endocrine and genetic strategies to increase fertility in the UK dairy herd. Vet. J. 180:356-362.

Norman, H. D., J. L. Hutchison, J. R. Wright, M. T. Kuhn, and T. J. Lawlor. 2007. Selection on yield and fitness traits when culling Holsteins during the first three lactations. J. Dairy Sci. 90:10081020.

Norman, H. D., J. R. Wright, S. M. Hubbard, R. H. Miller, and J. L. Hutchison. 2009. Reproductive status of Holstein and Jersey cows in the United States. J. Dairy Sci. 92:3517-3528.

Olori, V. E., T. H. E. Meuwissen, and R. F. Veerkamp. 2002. Calving interval and survival breeding values as measure of cow fertility in a pasture-based production system with seasonal calving. J. Dairy Sci. 85:689-696.

Petersson, K. J., B. Berglund, E. Strangberg, H. Gustafsson, A. P. F. Flint, J. A. Woolliams, and M. D. Royal. 2007. Genetic analyses of postpartum measures of luteal activity in dairy cows. J. Dairy Sci. 90:427-434.

Pryce, J. E., and R. F. Veerkamp. 2001. The incorporation of fertility indices in genetic improvement programmes. Pages 237-250 in Fertility in the High-Producing Dairy Cow. M. G. Diskin, ed. Br. Soc. Anim. Sci. Occasional Publication No. 26. Br. Soc. Anim. Sci., Penicuik, UK

Royal, M. D., A. O. Darwash, A. P. F. Flint, R. Webb, J. A. Woolliams, and G. E. Lamming. 2000. Declining fertility in dairy cattle: Changes in traditional and endocrine parameters of fertility Anim. Sci. 70:487-501.

Sewalem, A., G. J. Kistemaker, and F. Miglior. 2010. Relationship between female fertility and production traits in Canadian Holsteins. J. Dairy Sci. 93:4427-4434.

Sewalem, A., F. Miglior, G. J. Kistemarker, P. Sullivan, and B. J. Van Doormaal. 2008. Relationship between reproduction traits and functional longevity in Canadian dairy cattle. J. Dairy Sci. 91:1660-1668

Sun, C., P. Madsen, M. S. Lund, Y. Zhang, U. S. Nielsen, and G. Su. 2010. Improvement in genetic evaluation of female fertility in dairy cattle using multiple-trait models including milk production traits. J. Anim. Sci. 88:871-878.

VanRaden, P. M., A. H. Sanders, M. E. Tooker, R. H. Miller, H. D. Norman, M. T. Kuhn, and G. R. Wiggans. 2004. Development of a national genetic evaluation for cow fertility. J. Dairy Sci. $87: 2285-2292$ 